\title{
Establishment of an Anti-acne Vulgaris Evaluation Method Based on TLR2 and TLR4-mediated Interleukin-8 Production
}

\author{
PICHIT SUVANPRAKORN ${ }^{1}$, TITIPORN TONGYEN ${ }^{1}$, ORNJIRA PRAKHONGCHEEP ${ }^{2,3}$, \\ PANIDA LAORATTHAPHONG ${ }^{1}$ and PITHI CHANVORACHOTE ${ }^{2,3}$ \\ ${ }^{1}$ Pan Rajdhevee Group Public Co., Ltd., Pathumthani, Thailand; \\ ${ }^{2}$ Cell-Based Drug and Health Product Development Research Unit, \\ Faculty of Pharmaceutical Sciences, Chulalongkorn University, Bangkok, Thailand; \\ ${ }^{3}$ Department of Pharmacology and Physiology, Faculty of Pharmaceutical Sciences, \\ Chulalongkorn University, Bangkok, Thailand
}

\begin{abstract}
Background/Aim: To date, no cell-based assay that focuses on the prime cause of acne initiation through activation of toll-like receptor 2 and 4 and interleukin-8 (IL8) production exists. Herein, we present an assay that evaluates acne by determining TLR2 and 4 expression and activation. Materials and Methods: Viability of keratinocytes was determined by the MTT assay. IL-8 was evaluated by ELISA. Immunocytochemistry was performed for determining receptor expression. Results: Lipoteichoic acid (LTA), peptidoglycan (PGN) and lipopolysaccharide (LPS) induced IL-8 production. Pre-treatment of cells with TLR2 and TLR4 inhibitors, before stimulation, reduced IL-8 production. Zinc gluconate was used for verification. Zinc can significantly suppress IL-8 production in the system. Treatment of cells with LTA+PGN or LPS resulted in increased TLR2 and TLR4 expression on the cell surface. This effect was prevented by zinc treatment. Conclusion: The measurement of IL-8 and TLR2 and TLR4 levels can be used for the evaluation of anti-acne treatment.
\end{abstract}

Acne vulgaris is a chronic disease. It is common among adolescents and can have a huge impact on physical appearance and health both short-term and long-term as a result of the

This article is freely accessible online.

Correspondence to: Pithi Chanvorachote, Ph.D., Department of Pharmacology and Physiology, Faculty of Pharmaceutical Sciences, and Cell-based Drug and Health Product Development Research Unit, Chulalongkorn University, Bangkok 10330, Thailand. Tel: +662 2188344, Fax: +662 2188340, e-mail: pithi.c@chula.ac.th

Key Words: Acne vulgaris, host defense, keratinocytes, IL-8, TLR2, TLR4. adverse effects of the medication (1). The adverse effects are induced by non-anti-acne actions such as antibiotics and steroids (2). It is known that inflammation derived from the activation of innate immunity plays a primary role in the induction of acne lesions rather than infection or an allergic reaction (3). Clinically, there are multiple types of acne lesions. However, the induction of all types of lesions is primarily initiated by colonization of Propionibacterium acnes, a Gram-positive anaerobic bacterium that plays a key role in maintaining and influencing the inflammatory phase of acne (4). The major cell wall components of $P$. acnes, lipoteichoic acid (LTA) and peptidoglycan (PGN) were found to stimulate immune cells to release mediators of inflammation (5). Apart from LTA and PGN, lipopolysaccharide (LPS) - a component of gram-negative bacteria- is also an immunostimulatory factor (6).

The innate immune system of the skin epidermis has several defense components and mechanisms involving keratinocytes, neutrophils, mast cells and macrophages (7). The key step of acne formation is the interaction of bacterial components such as LPS, LTA or PGN with toll-like receptors (TLRs) in epidermal cells (8). TLR4 primarily mediates cellular signaling induced by Gram-negative bacteria (9), while TLR2 is required for pro-inflammatory signaling to components of Gram-positive bacteria (10). It is known that TLR2 and TLR4 are predominantly expressed on the cell surface of the infundibular keratinocytes. The activation of these TLRs results in signaling cascades that produce interleukin 8 (IL-8) (11). As a consequence, IL-8 acts as a pro-inflammatory cytokine and a powerful chemoattractant (12). This cytokine plays a major role in inflammatory events by its activity as chemokine and as an activator of crucial neutrophil functions (11).

So far, the anti-acne therapies mostly target bacteria. Based on the knowledge regarding the early activation of acne reaction through TLR2 and TLR4 leading to the IL-8 


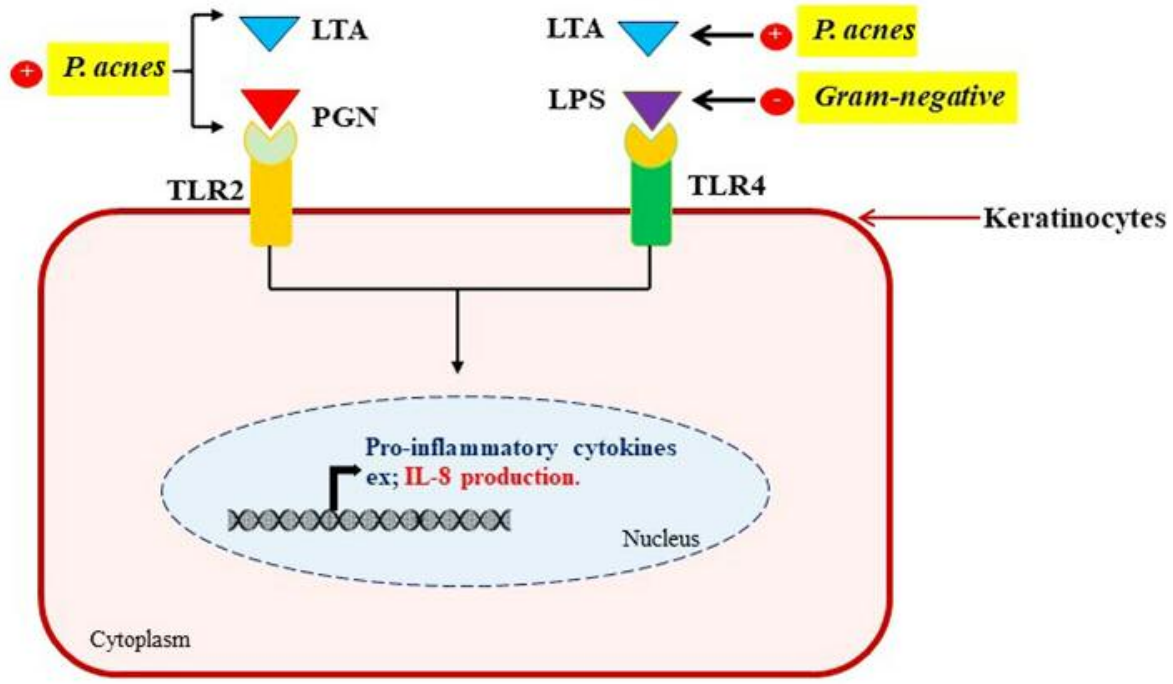

Figure 1. Schematic of the mechanism of IL-8 production via TLR2 and TLR4 activation.

production, we aimed at developing a method for evaluating anti-acne substances and specifically the cell signaling and the inflammatory response. The method includes evaluation of the effect of compounds on TLR2- and TLR4-mediated IL- 8 production and on the suppression of TLR 2 and TLR4 expression.

\section{Materials and Methods}

Cell culture. Human keratinocyte cell line HaCaT was purchased from the Cell Lines Service (CLS) GmbH (Eppelheim, Germany). HaCaT cells were cultured in Dulbecco's modified Eagle's medium (DMEM) (Gibco, Grand Island, NY, USA) supplemented with 10\% fetal bovine serum (FBS) (Merck, DA, Germany), $2 \mathrm{mM}$ L-glutamine and 100 units $/ \mathrm{ml}$ penicillin/streptomycin (Gibco). The cells were incubated at $37^{\circ} \mathrm{C}$ in a $\mathrm{CO}_{2}$ incubator $\left(5 \% \mathrm{CO}_{2}(\mathrm{v} / \mathrm{v})\right.$, $95 \%$ humidity in air). Cells were subcultured by trypsinization (Thermofisher Scientific, Waltham, MA, USA).

Cell viability assay. Cell viability was investigated by the MTT assay. Briefly, $\mathrm{HaCaT}$ cells were seeded into 96 -well plates at a density of $1 \times 10^{4}$ cells per well. The cells were treated with Zinc gluconate at various concentrations $(5,2.5$ and $1 \mu \mathrm{g} / \mathrm{ml})$ for $24 \mathrm{~h}$. Then, cells were incubated with $100 \mu \mathrm{l}$ of MTT solution for $3 \mathrm{~h}$ at $37^{\circ} \mathrm{C}$. After incubation, supernatants were removed and $100 \mu \mathrm{l}$ of DMSO was added in each well. The intensity was measured at wavelength of $570 \mathrm{~nm}$ by microplate reader (Anthros, Durham, NC, USA). The percentage of cell viability were calculated by comparison with untreated cells (control group).

Determination of IL-8 secretion by ELISA Kit. Signaling through the TLR2 and TLR4 results in increased production and secretion of IL-8 (Figure 1). Therefore to study the secretion of IL-8, cells sub-cultured and seeded into 96 -well plates at density of $8 \times 10^{3}$ cells per well were co-treated with inducers of TLRs [combination of LTA and PGN (10 $\mu \mathrm{g} / \mathrm{ml})$ ] and TLR2 inhibitor $(10 \mu \mathrm{g} / \mathrm{ml})$, TLR4 inhibitor $(10 \mu \mathrm{g} / \mathrm{ml})$, or zinc gluconate $(1.5 \mu \mathrm{g} / \mathrm{ml})$ for $24 \mathrm{~h}$. Also, cells were treated with LPS $(100 \mathrm{ng} / \mathrm{ml})$ in the presence of TLR2 inhibitor, TLR 4 inhibitor, or zinc gluconate for $48 \mathrm{~h}$ as shown in Figure 2A. After incubation, the supernatants were kept and IL- 8 levels were determined by using a sandwich ELISA system (R\&D systems, Minneapolis, MN, USA). Addition, untreated cells were also used as control.

Determination of TLR2 and TLR4. Cells were subcultured and seeded into 96 -well plates at a density of $8 \times 10^{3}$ cells per well. Then cells were treated with inducers (combination of LTA and PGN or LPS) in the presence of zinc gluconate as described in Figure 2B. Following treatment, cells were washed with $1 \mathrm{X}$ PBS, fixed with $4 \%(\mathrm{w} / \mathrm{v})$ paraformaldehyde for $15 \mathrm{~min}$ and permeabilized with $0.5 \%$ (v/v) Triton-X for $5 \mathrm{~min}$. Then, cells were incubated with $10 \%$ $(\mathrm{w} / \mathrm{v})$ FBS for $1 \mathrm{~h}$, washed and incubated with specific antibody against TLR2 or TLR4 (InvivoGen, San Diego, CA, USA) overnight at $4{ }^{\circ} \mathrm{C}$. Following washing cells were incubated with FITC and Texas Red (Abcam, Cambridge, UK) conjugated goat Human IgA H\&L or rabbit Anti-Rat IgG H\&L secondary antibody, respectively. Nuclei were stained with Hoechst 33,342 for $1 \mathrm{~h}$ at room temperature in the dark. Stained cells were washed, mounted with $50 \%$ glycerol, and visualized and captured using fluorescence microscopy (Nikon model ECLIPSE Ts2-FL, Tokyo, Japan).

Statistical analysis. The data were obtained from at least three independent experiments and are presented as the mean \pm standard deviation (SD). Statistical differences between two groups was determined by One-way analysis of variance (ANOVA) with a Tukey's test to compare the multiple groups at a significance level of $p<0.05$, 0.01 and 0.001 . Minitab version 16.0 was used for all statistical analyses.

\section{Results}

IL-8 production. HaCat keratinocyte cells at passages of 5-15 were stimulated by bacterial components and TLR2- and TLR4- 

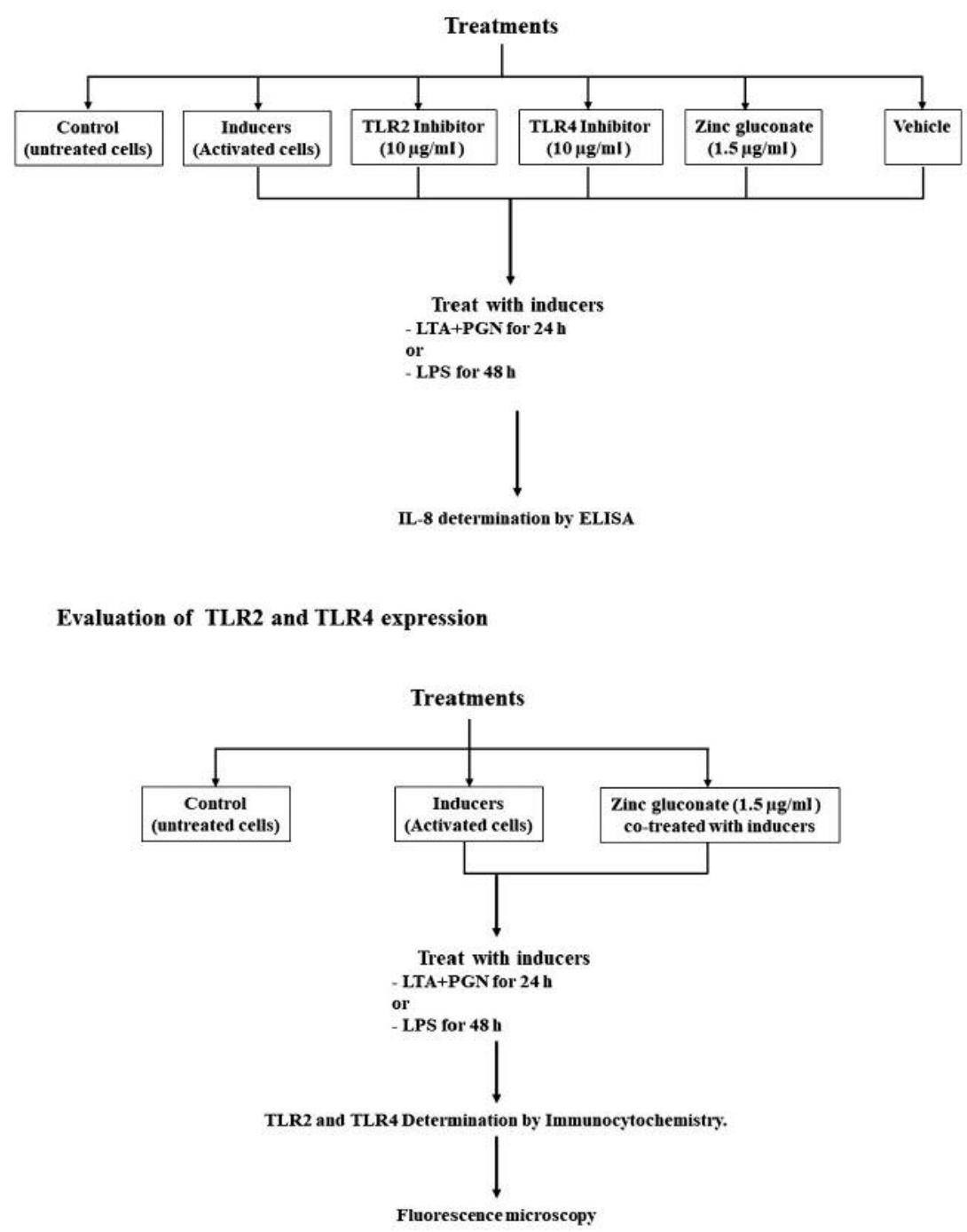

Figure 2. Design of the analysis assays. IL-8 induction assay (A), TLR2 and TLR4 expression assay (B).

mediated IL-8 production was measured (Figure 1). Following subculture and overnight incubation, the cells were treated with $5,2.5$ and $1 \mu \mathrm{g} / \mathrm{ml}$ of zinc gluconate for $24 \mathrm{~h}$ to determine its non-toxic doses. Cell viability was evaluated by MTT assay. As shown in Figure 3A, treatment with zinc gluconate at the indicated concentrations did not result in cytotoxicity. The monolayer of keratinocytes was exposed to LPS or LTA+PGN as shown in Figure 2, and IL-8 secretion was assayed in the supernatants by ELISA-immunoassay. As shown in Figure 3B and $\mathrm{C}$, the levels of IL- 8 protein in culture supernatants of untreated cells was very low. However, in the presence of LPS $(100 \mathrm{ng} / \mathrm{ml})$ or LTA+PGN $(10 \mu \mathrm{g} / \mathrm{ml})$, the secreted levels of IL-8 were significantly increased. Treatment of the cells with
TLR2 as well as TLR4 inhibitors dramatically suppressed production of IL-8, indicating that IL-8 production in keratinocytes is mediated via TLR2 and TLR4 activation. Zinc gluconate was also found to significantly suppress IL-8 production.

Evaluation of TLR2 and TLR4 expression on the surface of keratinocytes. Cell surface expression of TLR2 and TLR4 was examined in $\mathrm{HaCaT}$ cells using immunocytochemistry and fluorescence intensity analysis. LTA+PGN-treated cells (Figure 4) and LPS (Figure 5) showed higher intensity of fluorescence at the cell surface compared to control cells. Zinc gluconate suppressed the expression of the receptors at 


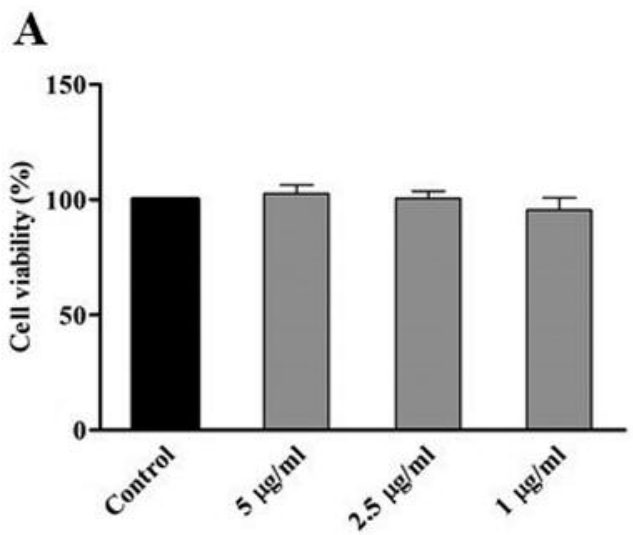

B

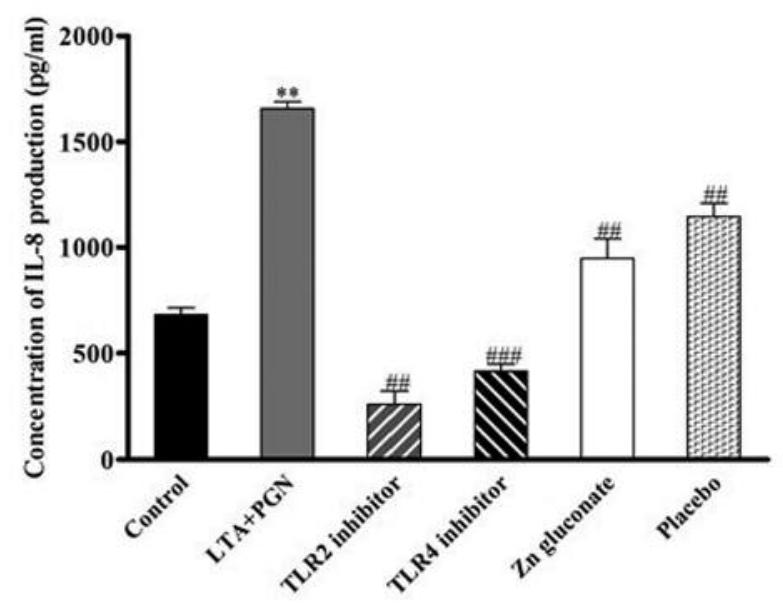

C

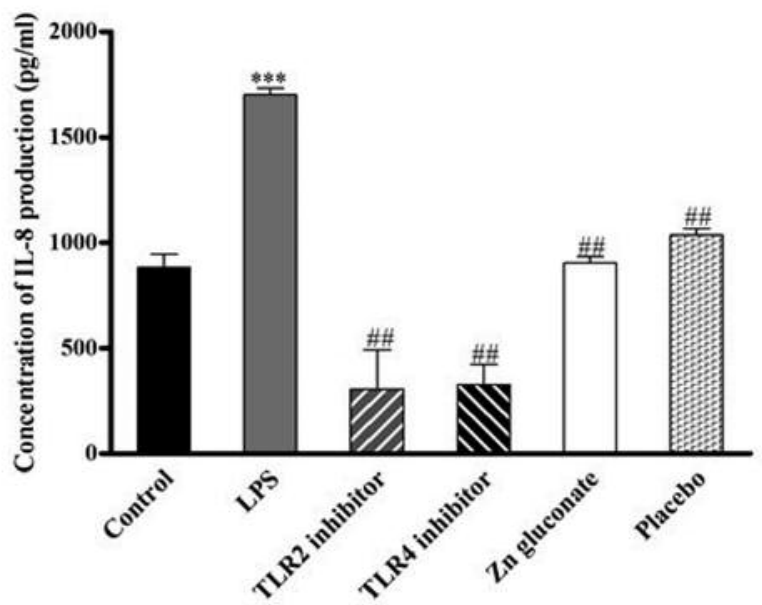

Figure 3. HaCaT cells were treated with 5, 2.5 or $1 \mu M$ of zinc gluconate for $24 \mathrm{~h}$. Cell viability was investigated using the MTT assay. Data represent the mean $\pm S D(n=3)(A)$. IL-8 secretion, assayed by ELISA, by HaCaT cells was induced following incubation with $10 \mu \mathrm{g} / \mathrm{ml}$ $L T A+P G N$ for $24 h(B)$ or $100 \mathrm{ng} / \mathrm{ml} L P S$ for $48 \mathrm{~h}(C)$. Co-treatment with $1.5 \mu \mathrm{g} / \mathrm{ml}$ zinc gluconate or solvent (ratio of 1:1,000). Data are presented as the mean $\pm S D(n=3)$. **p<0.01 vs. non-treated control.

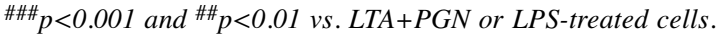

the cell surface.

\section{Discussion}

Acne vulgaris is a common disease that affects millions of people. It is a disease that has a significant impact on the psychological and physical well-being of patients (13). The pathogenesis of acne is multifactorial, including microbiological, hormonal and immunological mechanisms (14). The epidermis is an important site of interactions between microbes and the host and keratinocytes are one of the skin components that participate in host defense. They initiate and regulate the cutaneous inflammation and immune responses by producing cytokines (15). Microbes are the main organisms that lead to acne lesions. Gram-positive and anaerobic $P$. acnes have been implicated in acne inflammation and pathogenesis. LTA and PGN are the main components of $P$. acnes that trigger TLR2 activation and the release of the neutrophil chemoattractant cytokine IL-8 (16). On the other hand, LTA triggers TLR4 activation. In addition, LPS, a component of Gram-negative bacteria, also induces TLR4 activation (17). Therefore, the combination of LTA+PGN was chosen to simulate the effect of P. acnes. In order to select the appropriate concentrations of these compounds, viability of the treated cells should not be significantly different from untreated cells (control) (8). Zinc gluconate was initially screened using the MTT assay. The results showed that none of the concentrations of Zinc gluconate used had an effect on viability of HaCaT cells.

When skin is attacked by microbes, keratinocytes being at the first line of defense are activated and produce IL-8, a major cytokine which plays a role as a chemotactic factor to recruit immune cells (18). Therefore, IL-8 levels were determined by a sandwich ELISA. LPS and LTA+PGNtreated cells were found to produce and secrete increased levels of IL-8. Zinc gluconate-treatment decreased secretion of IL-8. A previous study has also reported that the induction of IL-8 depends on TLR family (19). Specifically, TLR2 and TLR4 that recognize bacterial cell-wall components, such as PGN, LTA and LPS. TLRs are also induced by endogenous ligands generated at sites of tissue inflammation that represent damage signals to the host (20). Interestingly, zinc gluconate treatment resulted in decreased expression of TLR2 and TLR4 at the cell surface when compared with the induced groups. These results indicated that zinc gluconate decreased IL-8 secretion via inhibition of TLR2 and TLR4 expression (Figure 1). As previously mentioned, the analyses performed in this study (Figure 2) are appropriate for estimating the efficacy of drugs against acne vulgaris. These analyses are simple and relatively short.

\section{Conflicts of Interest}

The Authors declare that there is no conflict of interest in regard to this research 

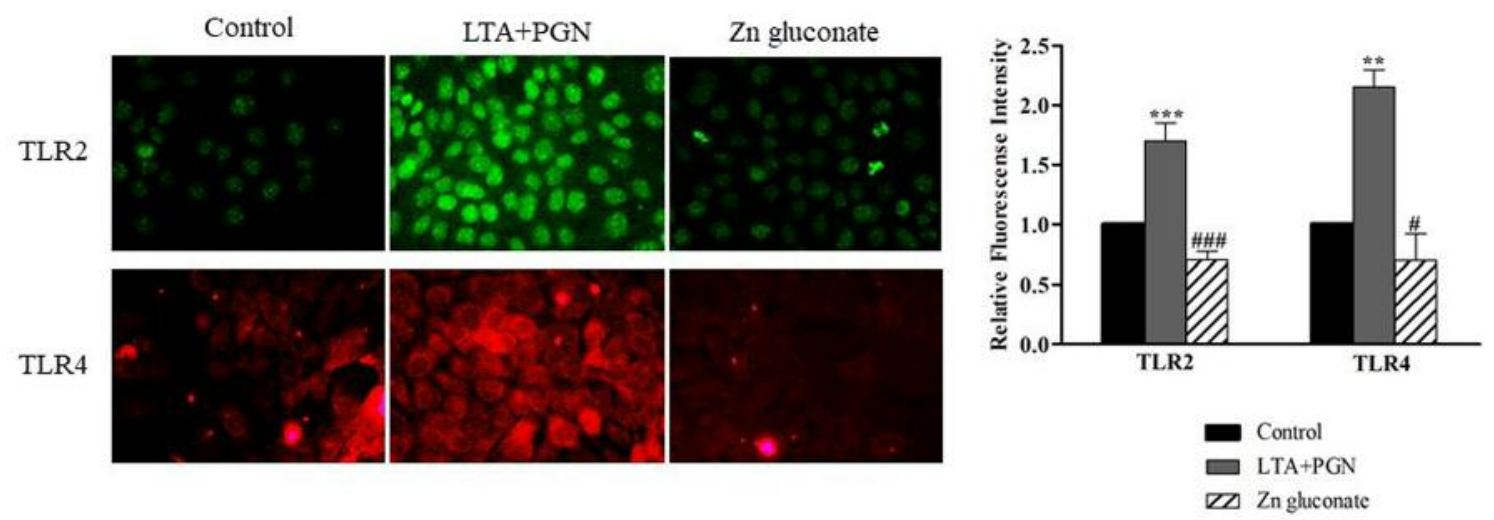

Figure 4. TLR2 and TLR4 expression levels were detected by polyclonal antibody specific for human TLR2 and TLR4, respectively and visualized by a fluorescence microscopy. Cells were activated by $10 \mu \mathrm{g} / \mathrm{ml} L T A+P G N$ for $24 \mathrm{~h}$. Data are presented as the mean $\pm S D(n=3)$. ***p<0.001 and ${ }^{* *} p<0.01$ vs. non-treated control. ${ }^{\# \#} p<0.001$ and ${ }^{\#} p<0.05$ vs. LTA $+P G N$.
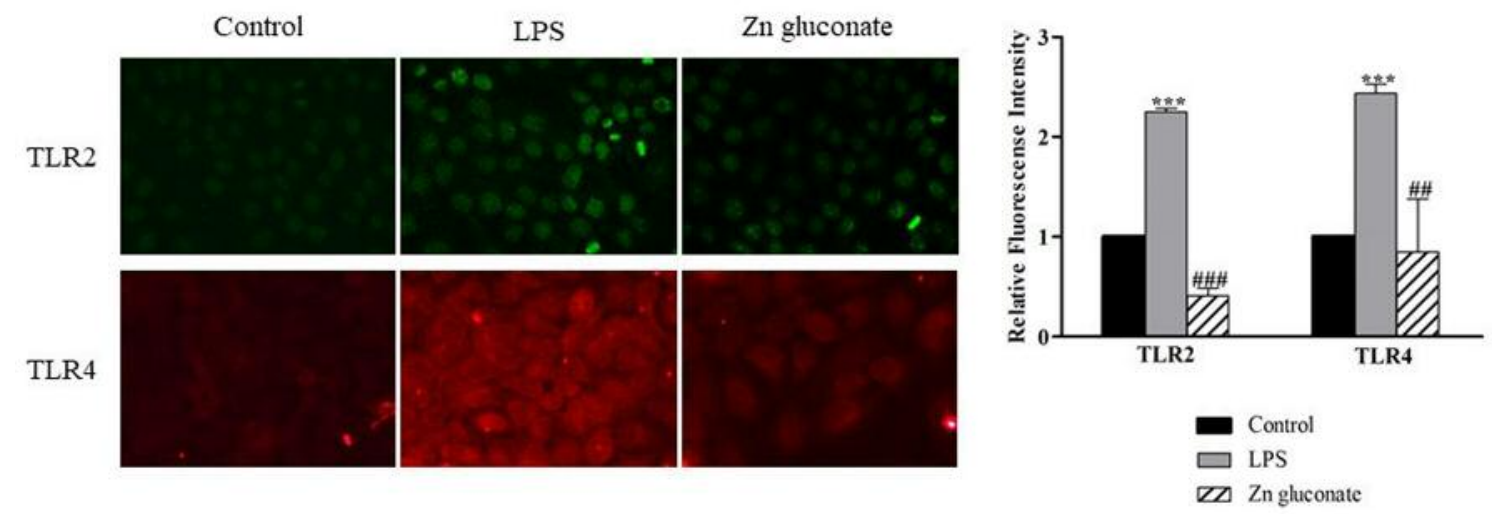

Figure 5. TLR2 and TLR4 expression levels were detected by polyclonal antibody specific for human TLR2 and TLR4, respectively and visualized by a fluorescence microscopy. Cells were activated by $100 \mathrm{ng} / \mathrm{ml} \mathrm{LPS}$ for $48 \mathrm{~h}$. Data are presented as the mean $\pm S D(n=3)$. ***p<0.001 vs. nontreated control. ${ }^{\# \#} p<0.001$ and ${ }^{\# \#} p<0.01$ vs. LPS-treated cells.

\section{Authors' Contributions}

PS and PC designed, analyzed, and concluded the experiments, TT and OP performed the experiments and drafted the manuscript. PL reviewed and concluded the experiments. PC concluded and revised the manuscript. All Authors approved the final version of the manuscript.

\section{Acknowledgements}

This research was funded by the Chulalongkorn University CU_GRS_61_08_33_01.

\section{References}

1 Lynn DD, Umari T, Dunnick CA and Dellavalle RP: The epidemiology of acne vulgaris in late adolescence. Adolesc
Health Med Ther 7: 13-25, 2016. PMID: 26955297. DOI: 10.2147/AHMT.S55832

2 Yuki T, Yoshida H, Akazawa Y, Komiya A, Sugiyama Y and Inoue S: Activation of TLR2 enhances tight junction barrier in epidermal keratinocytes. J Immunol 187(6): 3230-3237, 2011. PMID: 21841130. DOI: 10.4049/jimmunol.1100058

3 Pivarcsi A, Bodai L, Réthi B, Kenderessy-Szabó A, Koreck A, Széll M, Beer Z, Bata-Csörgoo Z, Magócsi M, Rajnavölgyi E, Dobozy A and Kemény L: Expression and function of Toll-like receptors 2 and 4 in human keratinocytes. Int Immunol 15(6): 721-730, 2003. PMID: 12750356. DOI: 10.1093/intimm/ dxg068

4 Kim J, Ochoa MT, Krutzik SR, Takeuchi O, Uematsu S, Legaspi AJ, Brightbill HD, Holland D, Cunliffe WJ, Akira S, Sieling PA, Godowski PJ and Modlin RL: Activation of toll-like receptor 2 in acne triggers inflammatory cytokine responses. J Immunol 169(3): 1535-1541, 2002. PMID: 12133981. DOI: 10.4049/ jimmunol.169.3.1535 
5 Seo HS, Michalek SM and Nahm MH: Lipoteichoic acid is important in innate immune responses to gram-positive bacteria. Infect Immun 76(1): 206-213, 2008. PMID: 17954723. DOI: 10.1128/IAI.01140-07

6 O'Neill AM and Gallo RL: Host-microbiome interactions and recent progress into understanding the biology of acne vulgaris. Microbiome 6: 1-16, 2018. PMID: 30285861. DOI: 10.1186/ s40168-018-0558-5

7 Michelsen KS, Aicher A, Mohaupt M, Hartung T, Dimmeler S, Kirschning CJ and Schumann RR: The role of toll-like receptors (TLRs) in bacteria-induced maturation of murine dendritic cells (DCS). Peptidoglycan and lipoteichoic acid are inducers of DC maturation and require TLR2. J Biol Chem 276(28): 2568025686, 2001. PMID: 11316801 DOI: 10.1074/jbc.M011615200

8 Phiboonchaiyanan PP, Petpiroon N, Sritularak B and Chanvorachote P: Phoyunnanin E induces apoptosis of nonsmall cell lung cancer cells via p53 activation and downregulation of surviving. Anticancer Res 38(11): 6281-6290, 2018. PMID: 30396948. DOI: 10.21873/anticanres.12984

9 Molteni M, Gemma S and Rossetti C: The role of toll-like receptor 4 in infectious and noninfectious inflammation. Mediat Inflamm 2016: 1-6, 2016. PMID: 27293318. DOI: 10.1155/ 2016/6978936

10 Nascimento LO, Massari P and Wetzler LM: The Role of TLR2 in Infection and Immunity. Front Immunol 3: 1-17, 2012. PMID: 22566960. DOI: 10.3389/fimmu.2012.00079

11 Mohamadzadeh M, Müller M, Hultsch T, Enk A, Saloga J and Knop J: Enhanced expression of IL-8 in normal human keratinocytes and human keratinocyte cell line $\mathrm{HaCaT}$ in vitro after stimulation with contact sensitizers, tolerogens and irritants. Exp Dermatol 3(6): 298-303, 1994. PMID: 7749573. DOI: 10.1111/j.1600-0625.1994.tb00292

12 Sukkar MB, Xie S, Khorasani NM, Kon OM, Stanbridge R, Issa $\mathrm{R}$ and Chung KF: Toll-like receptor 2, 3, and 4 expression and function in human airway smooth muscle. J Allergy Clin Immunol 118(3): 641-648, 2006. PMID: 16950283. DOI: $10.1016 /$ j.jaci.2006.05.013

13 Behnam B, Taheri R, Ghorbani R and Allameh P: Psychological impairments in the patients with acne. Indian J Dermatol 58(1): 26-29, 2013. PMID: 23372208. DOI: 10.4103/0019-5154.105281
14 Lovecková Y and Havlíková I: A microbiological approach to acne vulgaris. Biomed Papers 146(2): 29-32, 2002. PMID: 12572891. DOI: $10.5507 / \mathrm{bp} .2002 .005$

15 Bourke CD, Prendergast CT, Sanin DE, Oulton TE, Hall RJ and Mountford AP: Epidermal keratinocytes initiate wound healing and pro-inflammatory immune responses following percutaneous schistosome infection. Int J Parasitol 45(4): 215-224, 2015. PMID: 25575749. DOI: 10.1016/j.ijpara.2014.11.002

16 Dammermann W, Wollenberg L, Bentzien F, Lohse A and Lüth S: Toll like receptor 2 agonists lipoteichoic acid and peptidoglycan are able to enhance antigen specific IFN $\gamma$ release in whole blood during recall antigen responses. J Immunol Methods 396(1-2): 107-115, 2013. PMID: 23954282. DOI: 10.1016/j.jim.2013.08.004

$17 \mathrm{Lu} \mathrm{YC}$, Yeh WC and Ohashi PS: LPS/TLR4 signal transduction pathway. Cytokine 42(2): 145-151, 2008. PMID: 18304834. DOI: $10.1016 /$ j.cyto.2008.01.006

$18 \mathrm{Xu}$ W, Jia S, Xie P, Zhong A, Galiano RD, Mustoe TA and Hong SJ: The expression of proinflammatory genes in epidermal keratinocytes is regulated by hydration status. J Invest Dermatol 134(4): 1044-1055, 2014. PMID: 24226202. DOI: 10.1038/ jid.2013.425

19 Schaefer TM, Desouza K, Fahey JV, Beagley KW and Wira CR: Toll-like receptor (TLR) expression and TLR-mediated cytokine/chemokine production by human uterine epithelial cells. Immunology 112(3): 428-436, 2004. PMID: 15196211. DOI: $10.1111 / \mathrm{j} .1365-2567.2004 .01898 . \mathrm{x}$

20 Takeuchi O, Hoshino K, Kawai T, Sanjo H, Takada H, Ogawa T, Takeda K and Akira S: Differential roles of TLR2 and TLR4 in recognition of gram-negative and gram-positive bacterial cell wall components. Immunity 11(4): 443-451, 1999. PMID: 10549626. DOI: 10.1016/s1074-7613(00)80119-3

Received September 2, 2019

Revised September 23, 2019

Accepted September 24, 2019 